D.O.I.: $10.3895 / \mathrm{S} 1808-04482011000400007$

\title{
QUALIDADE EM SERVIÇOS: UMA ANÁLISE TEÓRICA SOBRE AS PRINCIPAIS CARACTERÍSTICAS
}

\section{QUALITY IN SERVICES: A THEORETICAL ANALYSIS ON THE MAIN FEATURES}

\author{
Luan Carlos Santos Silva ${ }^{1}$; João Luiz Kovaleski ${ }^{2}$; Silvia Gaia ${ }^{3}$ \\ ${ }^{1}$ Universidade Tecnológica Federal do Paraná - UTFPR - Ponta Grossa - Brasil \\ luancarlosmkt@gmail.com \\ ${ }^{2}$ Universidade Tecnológica Federal do Paraná - UTFPR - Ponta Grossa - Brasil \\ kovaleski@utfpr.edu.br \\ ${ }^{3}$ Universidade Tecnológica Federal do Paraná - UTFPR - Ponta Grossa - Brasil \\ gaia@utfpr.edu.br
}

\section{Resumo}

As empresas precisam estar conscientes das verdades que rodeiam quando se trata de qualidade em serviços. Pois, em primeiro lugar, deve-se ter em mente, que a satisfação do cliente não deve ser tratada somente por um determinado setor especifico da empresa, mais sim, a busca da qualidade nos serviços, deve-se ter o envolvimento e a preocupação de todos da empresa. Uma vez que, dentro da sua empresa deve-se deixar claro que "que os clientes não depende da sua empresa, mas sim, é a sua empresa que depende dos clientes". E por isso, deve ser responsabilidade de todos assegurarem satisfazer os seus clientes, e para este fim, aperfeiçoamento a qualidade nos serviços prestados. $O$ presente artigo foi desenvolvido com o intuito de identificar as principais características com relação a qualidade em serviços. A metodologia utilizada para realização do estudo acadêmico foi bibliográfico. Sendo que o objetivo principal deste artigo foi analisar os conceitos voltados a serviços, definindo sua importância no processo de satisfação dos clientes, abordando as características dos serviços, definição de qualidade, qualidade dos serviços, os sete pecados de um prestador de serviços, marketing de serviço ao cliente, e pesquisa do consumidor.

Palavras-chave: qualidade; serviços; análise.

\section{Introdução}

As empresas precisam estar conscientes das verdades que rodeiam quando se trata de qualidade em serviços. Pois, em primeiro lugar, deve-se ter em mente, que a satisfação do cliente não deve ser tratada somente por um determinado setor especifico da empresa, mais sim, a busca da qualidade nos serviços, deve-se ter o envolvimento e a preocupação de todos da empresa. Uma vez que, dentro da sua empresa deve-se deixar claro que "que os clientes não depende da sua empresa, mas sim, é a sua empresa que depende dos clientes". E por isso, deve ser responsabilidade de todos 
assegurarem satisfazer os seus clientes, e para este fim, aperfeiçoamnto a qualidade nos serviços prestados (KOTLHER, 1998, p.56).

A realidade do mercado está voltada para uma evidente competitividade com as quais as empresas buscam se destacar e sobressair do concorrente. Neste sentido, a qualidade dos serviços ganhou mais destaque e importância para empresas prestadoras de serviços. Pois, buscar a opinião expressa do cliente é também uma maneira que possibilita a sua conquista e fidelização.

Além disso, a qualidade em serviços é obtida a partir das diferentes ações que as empresas buscam executar e oferecer serviços com classe. Não esquecendo que o atendimento é o fator chave para qualquer empresa de qualquer que seja o ramo, pois é um quesito influenciador para a satisfação do cliente.

Desse modo, o presente artigo foi desenvolvido com o intuito de identificar as principais características com relação a qualidade em serviços.

A metodologia utilizada para realização do estudo acadêmico foi bibliográfico. Sendo que o objetivo principal deste artigo foi analisar os conceitos voltados a serviços, definindo sua importância no processo de satisfação dos clientes, abordando as características dos serviços, definição de qualidade, qualidade dos serviços, os sete pecados de um prestador de serviços, marketing de serviço ao cliente, e pesquisa do consumidor.

Ressalta-se que para Kotler a satisfação é dada através do "[...] sentimento de prazer ou de desapontamento resultante da comparação do desempenho esperado pelo produto ou serviço (ou resultado) em relação às expectativas da pessoa" (KOTLER, 1998, p. 53). A chave é equilibrar as expectativas do cliente com o desempenho da empresa. As empresas inteligentes têm como meta encantar os clientes, prometendo somente o que podem oferecer e depois oferecendo mais do que prometeram (KOTLER. 1999, p. 6). Além disso, o presente trabalho tem como objetivo específico analisar em qual dos setores os clientes estão mais satisfeitos com serviço prestado.

\section{Referencial teórico}

\subsection{Serviço: definição e importância}

Para não se ter dúvidas a respeito da diferença entre os bens e serviços segue então a seguite explicação, em geral os serviços, podem ser definidos como atos, esforços ou desempenhos, enquanto os bens, podem ser definidos como objetos, aparelhos ou coisas. Sendo a diferença primordial entre eles é a propriedade de tangibilidade. Ou seja, os bens tem caracter de tangível, pois possuem propriedades fisicas que podem ser sentidas, provadas e vistas antes da decisão de compra do cliente .Por exemplo, ao efetuar a compra de um comprar um carro, os clientes podem chutar os pneus, olhar o motor, ouvir o radio e levar o carro para um teste drive antes da decisão de compra. 
Em contraposição, os serviços tem dominância do intangível, e por isso, não possui propriedades fisicas que possasm ser avaliadas pelos clientes antes da compra (BERRY, 2001, p. $135)$.

Outras definições de serviços são sugeridas por diversos autores (GRONROOS, 1995, p.54), afirma que: "os serviços são atividades ou uma série de atividades em vez de objetos". E pelo fato de serem uma série de serviços e não um objeto é difícil gerenciar o controle da qualidade e fazer um programa de marketing. Eles são produzidos e consumidos, em até certo ponto de forma simultânea. Onde normalmente é quase que totalmente produzido quando o cliente está presente e recebe ou consome o serviço.

\subsection{Características dos serviços}

De uma forma figurativa, Fummersson, refere-se aos serviços da seguinte forma:

Os serviço são como algo que pode ser comprado e vendido, mas que você não consegue deixar cair sobre seu pé! Serviços são, essencialmente, intangíveis, embora possam estar associados a elementos tangíveis. Exemplos: decoração de um quarto de hotel, conforto de uma cama, higiene de um restaurante e aparência dos atendentes de uma loja (FUMMERSSON ,1987, p.72).

Há quatro características básicas de serviços, sendo elas segundo Cobra (1992, p.373):

a) Intangibilidade: Os serviços são intangíveis. Ao contrario dos produtos, os serviços não podem ser provados, apalpados, ouvidos ou cheirados entes de serem comprados. O principal desafio do homem de marketing é tornar os serviços tangíveis, através da localização física;

b) Inseparabilidade: os serviços são feitos e consumidos ao mesmo tempo , não podendo ser estocados para venda ou consumo posterior;

c) Variabilidade: os serviços são altamente variáveis, pois dependem de quem os realizam e quando e onde são realizados. Ou seja, nunca serão um igual ao outro, pois as pessoas são diferentes, as necessidades são variadas, os momentos são diferentes;

d) Perecibilidade: os serviços que não podem ser estocados são perecíveis. Esta característica torna-se um problema quando há período de baixa demanda.

Para Gianesi e Correa (1994, p.94), a presença do cliente, implica em um maior grau de participação do cliente no processo. O cliente é quem inicia o processo de prestação do serviço, pois o serviço só é produzido após a solicitação do cliente Os autores ainda afirmam, que a presença do cliente no processo de produção do serviço introduz um elemento não controlado pelo prestador do serviço e ainda acrescenta a necessidade de o cliente ficar satisfeito com a forma como o serviço é prestado (GIANESI; CORREA, 1994, p.94).

\subsection{Definição de qualidade}


Existem várias conceituações para o termo qualidade, este fato é que torna difícil manter uma posição definitiva para a idéia do que realmente seja a qualidade. O que se sabe ao certo é que a qualidade chegou para ficar, seja no trabalho, em casa, na produção de bens ou na prestação de serviços. Ou seja, em qualquer atividade humana, a qualidade tornou-se imprescindível.

Desde o início da abertura do mercado brasileiro à competição estrangeira, a partir de 1990, o que se observa são transformações na estratégia mercadológica das empresas nacionais. E isto vem acontecendo de acordo com a globalização das economias mundiais, exigindo das empresas que se candidatam à sobrevivência, um aumento de produtividade, redução de custos, padronização da qualidade dos produtos e preços mais baixos para o consumidor final.

Entretanto, esse mercado globalizado faz uma imposição ou até mesmo propõe um novo desafio para as empresas: "é o desenvolvimento de uma vantagem competitiva de modo que seja sustentável, ou seja, algo que o cliente perceba como um diferencial entre o produto de uma empresa e o da concorrência”. Segundo recentes pesquisas, o atendimento de qualidade ao cliente é o que determinará o crescimento das empresas na próxima década e a qualidade total é que garantirá essa permanência.

Talvez a definição mais básica sobre a condição do que é qualidade e dada por W. Edwards Deming, um pioneiro do movimento de qualidade na indústria, definiu em palavras simples que qualidade é "fazer o que é correto e da forma correta" (DEMING, 1990, p.38). Ou seja, oferecer um serviço que seja seguro, seria o correto e de modo que satisfaçam as necessidades dos clientes seria a forma correta.

Varias outras definições são propostas. Garvin (2002, p.64) em meio a tantas definições sintetizou a qualidade em cinco abordagens:

a) Abordagem Transcendental: a qualidade é vista como um sinônimo de excelência inata. Sendo definida como o melhor possível em termos da especificação do produto ou serviço;

b) Abordagem baseada na Manufatura: preocupa-se em fazer produtos ou prestar serviços que correspondem precisamente às especificações do projeto, livre de erros. A qualidade do produto está no cumprimento das especificações do projeto;

c) Abordagem baseada no Usuário: assegura que o produto ou serviço está adequado a seu propósito. A definição de qualidade está preocupada com a adequação das especificações ao consumidor e com a conformidade das especificações;

d) Abordagem baseada em Produto: a qualidade é vista como um conjunto mensurável de características que são requeridas para satisfazer o consumidor;

e) Abordagem baseada em Valor: a qualidade é definida em termos de custo e preço.

De acordo, Garvin (2002, p.81): 
A qualidade num primeiro momento, era vista fundamentalmente sob a ótica da inspeção, na qual, através de instrumentos de medição, tentava-se alcançar a uniformidade do produto; posteriormente, buscava-se através de instrumentos e técnicas estatísticas conseguir um controle estatístico da qualidade; a terceira etapa do movimento da qualidade está mais preocupada com a sua própria garantia. Para isso, coordena de forma tal todo o processo produtivo desde o projeto do produto até a sua chegada ao mercado consumidor; finalmente, a ênfase volta-se para o gerenciamento estratégico da qualidade, no qual a preocupação maior é poder concorrer num determinado mercado, buscando-se não só satisfazer as necessidades do consumidor, mas também a do próprio mercado.

E ainda, Kotler diz que:

O nível de qualidade que se deseja alcançar num determinado produto necessita estar em consonância com o mercado-alvo que se quer atingir. A qualidade significa que o mesmo seja capaz de mostrar um alto desempenho, através de alguns critérios, tais como: durabilidade, confiabilidade, precisão, facilidade de operação e reparos etc. Acima de tudo, a qualidade precisa ser medida do ponto de vista do consumidor uma vez que, somente sob a sua ótica é que se pode medir a qualidade em geral. Vale destacar que a verdadeira "qualidade está além de uma simples redução de defeitos: significa, pois, satisfazer os desejos e necessidades dos clientes melhor que os concorrentes (Kotler, 1998, p. 176).

O conceito de qualidade pode ser sintetizado como sendo "um produto ou serviço de qualidade é aquele que atende perfeitamente, de forma confiável, de forma acessível, de forma segura e no tempo certo às necessidades do cliente". Isso significa para o mesmo: um projeto perfeito; sem defeitos; baixo custo; segurança do cliente entrega no prazo certo, no local certo e na quantidade certa.

Além de tudo, vale ressaltar algumas considerações imprescindíveis sobre a qualidade, pois para compreender com exatidão o seu conceito segue algumas explanações sobre a qualidade interna e externa.

Segundo Garvin (2002. p. 44), para a obtenção da qualidade interna faz-se necessário cumprir algumas etapas, quais sejam: determinar, com a maior precisão possível, quais são as necessidades, desejos e expectativas dos consumidores; converter essas características em especificações do desenho; adequar os processos de produção para cumprir com precisão essas especificações e finalmente estabelecer normas ou parâmetros de qualidade que permitam controlar a produção no sentido de que a mesma se ajuste a essas especificações e evitem que se comercializem produtos que não cumpram com essas normas.

E a qualidade externa pode ser definida como a forma pela qual se realiza a prestação do serviço. Significa identificar as características que possui o produto quando da entrega ao cliente.

Ainda de acordo com pensamento de Garvin (2002), essas características podem ser mais bem visualizadas quando se leva em consideração as dez dimensões da qualidade externa. São elas:

a) Aspectos físicos (aparência de instalações, pessoal, equipes, disposição dos materiais);

b) Confiabilidade (habilidade para realizar o serviço prometido de forma confiável e de acordo com as normas técnicas do setor);

c) Capacidade de resposta (disposição para ajudar o cliente e oferecer um serviço rápido e a tempo); 
d) Profissionalidade (posição demonstrada dos conhecimentos e habilidades que permitem realizar o serviço com eficácia);

e) Cortesia (respeito, consideração e sentido de simpatia e amizade que se demonstra aos clientes);

f) Credibilidade (confiança, fé,honestidade que a empresa projeta no seu pessoal e nos serviços que presta);

g) Seguridade (ausência de danos, riscos, incertezas); acessibilidade (disponibilidade e Facilidade de contato com a empresa e seus diretores);

h) Comunicações (capacidade para manter os clientes informados em uma linguagem que podem entender e tenham disposição para lhes escutar);

i) Compreensão do usuário (esforços que se realizam para conhecer, com a maior amplitude possível, as necessidades, desejos e expectativas dos usuários (GARVIN, 2002, p.87).

Portanto, para que uma determinada empresa que esta no mercado no ramo de prestação de serviços é essencial que se adote de forma mais rápida possível o conceito de qualidade interna e externa. Assim, adotando essas medidas é que poderá ter êxito a longo prazo.

Com tudo, observa-se que esses conceitos de qualidade, mostram como é importante que as empresas precisam ter uma visão mais ampla voltada para esses contexto interno (a qualidade do produto) e externo (a prestação do serviço ao cliente), uma vez que, o setor de serviços tem aumentado muito nos últimos tempos, e estas características da qualidade são as novas tendências de mercado, por isso, as empresas devem inserir-se neste novo ambiente visando alcançar a sobrevivência a longo prazo (Garvin, 2002, p. 89).

\subsection{Qualidade dos serviços}

De acordo com Gianesi e Corrêa (1996):

A qualidade em serviços pode ser definida como o grau em que as experiências do cliente são atendidas por sua percepção do serviço prestado. Basear a definição de qualidade nas expectativas do consumidor pode ser um problema, já que cada consumidor pode ter uma expectativa. Porém, a qualidade precisa ser entendida do ponto de vista do consumidor, pois, é este que vai avaliar o serviço através da sua percepção (GIANESI; CORRÊA, 1996, p.81).

Os serviços dificilmente podem ser avaliados antes da compra dando-se a avaliação durante o processo de prestação do serviço ou, em alguns casos, somente após ser conhecido o seu resultado e até existem os serviços que não podem ser avaliados pelo cliente, nem mesmo após o seu término (GIANESI; CORRÊA, 1996, p.81).

Portanto, a qualidade do serviço e sua avaliação são feitas pelo cliente e dão-se através da conferência equiparada entre o que o cliente aguardava e o que percebeu do serviço oferecido. Neste contexto, um fator importante é a característica de intangibilidade do serviço, já que as expectativas relacionadas ao serviço vão se basear na comunicação transmitida ao cliente. Sem nenhuma concepção os conceitos de satisfação do cliente estão intimamente entrelaçados com a qualidade do serviço prestado.

No entanto, esta qualidade só poderá ser compreendida sob o olhar clínico do consumidor, 
uma vez que, que somente ele como consumidor pode diagnosticar através de sua percepção e experiência a qualidade do serviço prestado. A qualidade dos serviços proporciona uma maneira de alcançar o sucesso entre os serviços dos concorrentes. Particularmente quando um número pequenos de empresas que oferecem serviços idênticos esta competindo em uma área pequena. Assim, estabelecer a qualidade do serviço pode ser a única maneira de se diferenciar.

Além disso, o elemento mais importante em demonstrar consistentemente é a competência nos serviços e isso inclui a dependência de mão-de-obra qualificada. Os seres humanos oferecem um serviço mais variável do que as máquinas. Essa é uma realidade da condição humana. Não apenas as pessoas que prestam serviços diferem uma das outras quanto as suas atitudes, personalidades e habilidades nos serviços, mas o mesmo prestador de serviço pode fornecer diferentes niveis de qualidade de serviço de um cliente para outro, dependendo da atitude em particular do cliente, da complexidade do serviço solicitado, do cansaço do prestador de serviço ou dos problemas pessoais.

Em resumo, os serviços altamente dependente de mão-de-obra são mais vulneraveis a apresentar falhas. Muitas empresas fornecem serviços altamente dependente de mao-de-obra em diverso setores visitados pelos clientes. Sabendo que não se encontra facilmente competencia no serviço, os clientes agarram a ela quando a encontram. A competencia no serviço constrói a confiança do cliente da empresa em manter suas promessas (BERRY, 2001, p.35).

À medida que muitas empresas venham a oferecer uma solução técnica similar, a excelência técnica poderá não ser mais um fator de diferenciação. É aí que entra a qualidade dos serviços como uma estratégia competitiva. Pois, numa concorrência entre duas empresas que fornecem um produto similar e com a mesma qualidade técnica, ganhará mercado aquele que fornecer um serviço de maior qualidade.

\subsection{Sete pecados de um prestador de serviços}

Para Albrecht Karl (1992), em seu artigo defini os sete pecados do prestador de serviço da forma abaixo:

a) Demonstrar apatia ocorre quando os funcionários de uma empresa não demonstram que se importa com o cliente. As pessoas ficam bravas, ofendem-se;

b) Demonstrar rejeição ou má vontade: tentar livrar-se do cliente desprezando-o, ou seja, a velha síndrome do "quero que você vá embora", sem resolver o problema;

c) Demonstrar frieza: prestadores de serviços indiferentes que parecem não se importar com o que cliente realmente quer. O Cliente é tratado de forma distante e as vezes até de maneira desagradável;

d) Demonstrar ar de superioridade: desdém há funcionários que se dirigem ao cliente, de 
cima para baixo, como se o cliente não soubesse nada, fosse uma criança. Isso enfurece as pessoas;

e) Demonstrar Robotismo: o funcionário deixa de agir como se fosse uma pessoa e repete sempre à mesma coisa, da mesma maneira e com os mesmos movimentos;

f) Demonstrar o jogo do empurra: ou seja, passar o cliente para outro funcionário, que também vai simplesmente passa-lo para outro. É a síndrome do vai-para-lá e vem-para-cá. Há pessoas que mandam os clientes de um lugar para o outro, sem nunca resolver nada;

g) Demasiado apego às normas: acontece com o funcionário que diz "sinto muito, mas não podemos ser flexíveis.

Assim, percebe-se claramente que os setes pecados de um prestador de serviço é cometido através de demonstrações, ficando assim comprometido a sua atuação perante o cliente uma vez que o mesmo perceber tal demonstração certamente a sua empresa cometeu um pecado que pode comprometer o seu sucesso.

\subsection{Marketing de serviço ao cliente}

Alguns fatores parecem afetar a qualidade dos serviços de produção ou prestação de serviços nas empresas. Kimmons (2008) identificou o tamanho de uma empresa como uma consideração importante na escolha da empresa para se trabalhar com serviços. De acordo com o autor, as grandes empresas vai desenvolver mais negócios em comparação com os empresas menores.

Nas palavras de Uusitalo (2001), os consumidores analisam o tamanho da empresa para orientar sua percepção e avaliação de uma empresa para outra. Devido à importância da dimensão da empresa em percepção dos consumidores. Abu (2004) em sua tese sobre o tamanho da empresa, utilizou-se como base de categorização para a avaliação dos consumidores, a qualidade do serviço das empresas.

De acordo com Odekerken Schroder et al. (2001), grandes empresas são vistas como dando mais simbologia e padrão ao consumidor. O tamanho de um ambiente físico tem visto por Forgas (1979), como um fator que influencia o grau de interação social entre clientes e funcionários.

Daharwal (2006) observou que a propaganda "marketing dos serviços" é um importante recurso utilizado para promover a venda de um produto ou serviço. A publicidade é uma arte usada para familiarizar o público com o produto, informando de sua descrição usos, a sua superioridade sobre outras marcas, fontes de sua disponibilidade e preço etc. Também pode ser definida como a divulgação de informações sobre uma idéia, serviços ou produtos para obrigar medidas em conformidade com o interesse dos anunciantes.

O marketing de serviços é uma ferramenta poderosa que as organizações utilizam para informar, persuadir e lembrar seu público-alvo sobre suas atividades no mercado. De acordo com Mathews (2006), o consumidor de médio porte não seria capaz de saber o que comprar, sem 
anúncio. Daharwal (2006) e Nowak (2008) observou algumas vantagens do marketing de serviço, incluindo: ajudar na introdução de novos produtos e serviços no mercado; promove a venda de bens e serviços, persuadir as pessoas a comprá-los; ajudar na criação de uma demanda e, portanto, uma produção regular; permitir que uma empresa possa enfrentar a concorrência no o mercado para a sua sobrevivência; permitir que uma empresa possa melhorar a sua reputação, destacar as suas conquistas para o público, e ajudar a manter a uniformidade e estabilidade de preços, ganhando mais competitividade no mercado alvo.

Assim afirma Walker (1991, p.1), que a vantagem competitiva pode basear-se em uma diferença perceptível de satisfazer melhor que os concorrentes as necessidades identificadas do cliente. E completa dizendo que isso só pode acontecer se os serviços forem tratados como uma questão estratégica e forem acionados mecanismos para tornar os serviços um valor-chave da organização.

Dessa forma, percebe-se que as empresas voltadas para o ramo de prestação de serviços precisam encontrar uma maneira que façam com que os seus serviços se tornem um fator chave principal e de grande valorização. No entanto, para que isto aconteça é necessária à elaboração de estratégias voltadas para este ângulo. E a essência dessa estratégia é poder enxergar a empresa pelo ângulo do cliente e poder se preparar melhor para atendê-lo.

Uma vez que a qualidade tangível dos produtos/serviços ofertados pelas empresas é bastante similar, senão iguais, o "diferencial está no "algo mais" que a empresa oferece ao seu cliente, no intuito de garantir a sua fidelidade" (ALBRECHT; BRADFORD, 1992, p.42). E esse diferencial pode ser justamente o "atendimento das necessidades e satisfação do cliente, tanto dentro da loja, no momento de aquisição do produto/serviço, quanto fora, quando o cliente deve sentir-se satisfeito" (ALBRECHT; BRADFORD. 1992, p. 58).

Os mesmos autores ainda afirmam, que as empresas devem ser vistas pelos diretores e gerentes com os olhos dos clientes. As empresas bem-sucedidas fazem o máximo para criar esquemas compartilhados de referências. "Elas se esforçam para enxergar a empresa pelo ângulo dos seus clientes".

A gerência de serviços cria uma organização centrada no cliente, com foco nas suas necessidades e expectativas (ALBERECHT; BRADFORD, 1992, p.89). Sendo os "momentos da verdade" como resultados disso, e definem um momento da verdade como :

Precisamente aquele instante em que o cliente entra em contato com qualquer setor do seu negócio e, com base nesse contato, forma uma opinião sobre a qualidade do serviço e, possivelmente, da qualidade do produto (ALBRECHT; BRADFORD, 1992, p.28).

Esses momentos da verdade são aqueles em que todo funcionário da empresa se encontra frente a frente com o cliente. "Um esquema de referência comum, onde valores, sentimentos, 
crenças, expectativas para ambas as partes é o que determinara o sucesso ou não da situação". Sendo estes momentos muito importantes, pois é exatamente quando o cliente tem a percepção do serviço prestado. E se houver falhas em um desses momentos, a qualidade do serviço pode ser percebida pelos clientes como um serviço de baixo nível.

Assim, um bom marketing de serviço ao cliente apresenta-se como o melhor meio de criar esse um esquema de referências fazendo uma antecipação dos "momentos da verdade", permitindo prever como e quando ocorrerão.

Conforme Albrecht e Bradford (1992, p.28), em serviços utiliza-se os 8 (oito) Ps como uma estratégia para definição de ações. Sendo eles:

a) Produto (sendo todos os componentes que fazem parte do desempenho de serviço que criam valor para os clientes);

b) Praça (trata-se do lugar e tempo, ou seja, quando, onde e como oferecer serviços aos clientes);

c) Processo ( sendo o método e a seqüência em que um sistema operacional funciona);

d) Produtividade (é o grau de eficácia com que os insumos de serviços são transformados em valor adicionado a produtos e qualidade, ou seja, o grau no quais as necessidades, os desejos e as satisfações do cliente se equilibra);

e) Pessoas (são os clientes e empregados envolvidos na produção de serviços);

f) Promoção (todas as atividades e incentivos projetado para aumentar a preferência do cliente;

g) Percepção (é a evidência física, são sinais do que é tangível que dêem evidencia de qualidade de serviços);

h) Preço ( é o dinheiro, tempo e esforço gastos pelos clientes).

\subsection{Pesquisa do consumidor: o primeiro passo paro qualidade em serviços}

As pesquisas de satisfação tramitem aos clientes a mensagem de que a empresa preocupa-se com o bem estar deles e valorizam a contribuição a respeito dos seus processos de prestação de serviço (LAS CASAS , 2001, p.153).

Além disso, as pesquisa de satisfação de clientes estão inserida dentro de um sistema de administração de informações que constantemente objetiva captar a voz do cliente, visando avaliar o desempenho da empresa sob a ótica do cliente. A pesquisa tem seu foco voltado para medir a qualidade de desempenho da empresa em seus negócios, onde indica caminhos para as decisões futuras de comercialização e marketing. No entanto, o mais importante das pesquisas e o fato de ser um processo que visa verificar o nível de satisfação dos clientes.

Vale lembrar que, existem outros benefícios proporcionados pelas pesquisas de satisfação de 
clientes, como: "percepção mais positiva dos clientes quanto à empresa; informações precisas e atualizadas quanto às necessidades dos clientes; relações de lealdade com os clientes, baseadas em ações corretivas; e confiança desenvolvida em função de maior aproximação com o cliente"

Elas estão intimamente ligadas aos processos de qualidade, que fortalecem a competitividade as empresas, "as pesquisas sobre a satisfação de clientes insere-se entre os prérequisitos que sustentam ações eficazes de marketing” (CZINKOTA, 2001, p.110-111).

Contudo, os resultados das pesquisas são catalogados aos procedimentos capazes de certificar que o processo de satisfação do cliente da empresa "começa com o input qualitativo e quantitativo dos clientes, dos empregados que interagem com esses clientes e com os clientes dos concorrentes; desenvolve planos de ação para melhorar o que os clientes dizem que deve ser melhorado; motiva e capacita os empregados a satisfazer os clientes, vinculando avaliação de desempenho e compensação com o cumprimento do plano de ação (CZINKOTA, 2001, p.109-110).

A marca de um verdadeiro profissional, independente de qual sela o seu negócio, é reconhecer que as melhores informações comerciais que você pode obter nunca são encontradas em um relatório ou em uma informação de segunda mão, é através de uma constante de informações diretas, imediatas, por parte de seus clientes ( ROSSI, 1995, p.42).

Assim as pesquisas passam a ser a marca verdadeira de profissional que não tem receio de ouvir a opinião expressa pelas pessoas a respeito de sua empresa. As pesquisas são uma forma estruturada e formal de reunir feedback sobre experiências dos Clientes, suas opiniões sobre produtos e serviços da sua empresa e sua satisfação geral de Relacionamento (CZINKOTA, 2001, p.109-110).

Por isso, deve haver uma constante necessidade de se saber a respeito dos consumidores, o que eles valorizam e o que querem em determinado momento. Avaliar o grau de satisfação do seu público é melhor meio para sobreviver em um mercado cada vez mais competitivo (LAS CASAS, 2001, p.153).

\section{Metodologia}

A pesquisa assumiu natureza descritiva. A metodologia utilizada para realização do estudo acadêmico foi bibliográfico. Sendo que o objetivo principal deste artigo foi analisar os conceitos voltados a serviços, definindo sua importância no processo de satisfação dos clientes, abordando as características dos serviços, definição de qualidade, qualidade dos serviços, os sete pecados de um prestador de serviços, marketing de serviço ao cliente, e pesquisa do consumidor.

No primeiro momento, a pesquisa consistiu da analise de fontes secundarias, tais como referencias bibliográfica e pesquisas realizadas oriundas de outras fontes. No segundo momento, as referencias analisadas no marco teórico serviu como base para analise às informações diretamente 
com o objeto de estudo.

Desse modo, o presente artigo foi desenvolvido com o intuito de identificar as principais características com relação a qualidade em serviços.

\section{Considerações finais}

A partir das analises deste estudo, buscou-se contextualizar por meio da literatura existente, um entendimento maior dos conceitos voltados à qualidade em serviços, definindo sua importância no processo de satisfação dos clientes, abordando suas características e definições.

O que vem a confirmar a teoria de Rossi (1995, p.352), pois a satisfação do cliente é portanto, expressada a partir de suas percepções com relação ao desempenho de um conjunto de fatores que quando avaliados atingem, superam ou ficam aquém do esperado.

Kotler (2002, p. 85), conclue explicando o que há falhas nas empresas, pois segundo ele, satisfazer cliente além de descobrir o que ele deseja, é preciso melhorar continuamente o desempenho do serviço da sua empresa, esse resultado só será positivo quando a empresa e os funcionários estiverem comprometidos com o objetivo de servir bem, proporcionando o melhor atendimento.

À medida que muitas empresas venham a oferecer uma solução técnica similar, a excelência técnica poderá não ser mais um fator de diferenciação. É aí que entra a qualidade dos serviços como uma estratégia competitiva. Pois, numa concorrência entre duas empresas que fornecem um produto similar e com a mesma qualidade técnica, ganhará mercado aquele que fornecer um serviço de maior qualidade.

Contudo, acredita-se que este artigo além de contribuir com o conteúdo bibliográfico, com os dados obtidos através da revisão da literatura, também contribuirá imensamente para a academia e gestores das empresas, pois são dados importantes dos quais apresentam informações necessário sobre o processo de qualidade em serviços na busca da satisfação dos clientes nas empresas.

\footnotetext{
Abstract

Companies need to be aware of the truths that surround when it comes to quality services. For in the first place, it should be borne in mind that customer satisfaction should not be treated only by a certain sector specific company, but rather, the pursuit of quality services, are likely to have the involvement and concern everyone in the company. Once inside your company should be made clear that "customers do not depend on your company, but is that your company depends on the clients." And so it should be everyone's responsibility to ensure satisfying their customers, and to this end, improving the quality of services provided. This article was developed in order to identify key characteristics with respect to service quality. The methodology used for the study was academic literature. Since the main objective of this study was to analyze service-oriented concepts, defining its importance in customer satisfaction by addressing the characteristics of services, definition of quality, service quality, the seven sins of a service, marketing customer service, and consumer research.
} 
Key-words: quality; services; analysis.

\section{Agradecimento}

Agradecemos ao Conselho Nacional de Desenvolvimento Científico e Tecnológico (CNPq) pelo apoio financeiro.

\section{Referências}

ABU, N. K. Service quality dimensions: A Study on Various Sizes of Grocery Retailers. Faculty of Business Administration, University Tun Abdul Razak, Kelana Jaya, Selangor, Malaysia. 2004.

ALBRECHT, Kl.; BRADFORD, L. Serviço com qualidade. 5 ed. São Paulo: Makron Books, 1992.

BERRY, L. Descobrindo a essência do serviço. $2^{a}$ ed. São Paulo: Qualitymark, 2001.

COBRA, M. Administração de marketing. $2^{\circ}$ ed. São Paulo: Atlas.1992.

CZINKOTA, M. R. Marketing as melhores práticas. São Paulo: Bookman, 2001.

DAHARWAL, S. J. Internet marketing newsletter. Disponível em: 〈www.internetmarketingnewsletter.com>. Acesso em: 23 jul. 2011.

DEMING, W. E. Qualidade: a revolução da Administração. Rio de Janeiro: Marques Saraiva, 1990.

FORGAS, J. P. Social Episodes, London, Academic Press, Inc., in Bitner, M.J. (1992). Services capes: The Impact of Physical Surroundings on Customers and Employees. Journal of Marketing, v.56, p.57-71. 1979.

GARVIN, D. Gerenciando a qualidade. $1^{\mathrm{a}}$ ed. São Paulo. QualityMark, 2002.

GIANESI, I. G. N.; CORRÊA, H. L. Administração estratégica de serviços. 2ªd. São Paulo: Atlas, 1996.

GRÖNROOS, C. A. Marketing - gerenciamento e serviços: a competição por serviços na hora da verdade. Rio de Janeiro: Campus, 1995.

KIMMONS, J. Choosing a commercial real estate firm. Looking at Brokerage Size, Small or Large - Which is Right for You? 2008.

KOTLER, P. Administração de marketing. $5^{\text {a }}$ ed. São Paulo: Atlas, 1998/2000.

LAS CASAS, A. Marketing. 5ª ed. São Paulo: Atlas, 2001.

MATHEWS, M. Advertising's role in business, society. Disponível em: 〈http://www.associatedcontent.com〉. Acesso em: 07 ago. 2011.

NOWAK, A. The role of words in advertising. Free Online Articles Directory. Disponível em: <www.articlebase.com>. Acesso em: 29 set. 2011.

ODEKERKEN-SCHRODER, G. DE W. K.. et al.. The impact of quality on store loyalty: a contingency approach. Total Quality Management, v.12 n.3, p.307-322. 2001.

UUSITALO, R. Homo entrepreneurs. Applied Economics, v.33, n.56, p.1631-1638. 2001.

cross ref

WALKER, D. O cliente em primeiro lugar. São Paulo: Makron Books, 1991. 


\section{Dados dos autores:}

Nome completo: Luan Carlos Santos Silva

Filiação institucional: Universidade Tecnológica Federal do Paraná - UTFPR.

Departamento: Programa de Pós-graduação em Engenharia de Produção - PPGEP/UTFPR.

Função ou cargo ocupado: Pesquisador/bolsista em Transferência de Tecnologia - CNPq.

Endereço completo para correspondência (bairro, cidade, estado, país e CEP): Av. Monteiro

Lobato, s/n, Campus Universitário, Ponta Grossa, Paraná, Brasil, CEP: 84.015-480

Telefones para contato: (42) 9959-9580; (42) 8810-5781

e-mail: luancarlosmkt@gmail.com

Nome completo: João Luiz Kovaleski

Filiação institucional: Universidade Tecnológica Federal do Paraná - UTFPR.

Departamento: Programa de Pós-graduação em Engenharia de Produção - PPGEP/UTFPR.

Função ou cargo ocupado: Professor e Coordenador do Programa de Pós-graduação em Engenharia de Produção - PPGEP/UTFPR

Endereço completo para correspondência (bairro, cidade, estado, país e CEP): Av. Monteiro

Lobato, s/n, Campus Universitário, Ponta Grossa, Paraná, Brasil, CEP: 84.015-480

Telefones para contato: (42) 3220-4800

e-mail:kovaleski@utfpr.edu.br

Nome completo: Silvia Gaia

Filiação institucional: Universidade Tecnológica Federal do Paraná - UTFPR.

Departamento: Programa de Pós-graduação em Engenharia de Produção - PPGEP/UTFPR.

Função ou cargo ocupado: Professora do Programa de Pós-graduação em Engenharia de Produção PPGEP/UTFPR.

Endereço completo para correspondência (bairro, cidade, estado, país e CEP): Av. Monteiro

Lobato, s/n, Campus Universitário, Ponta Grossa, Paraná, Brasil, CEP: 84.015-480

Telefones para contato: (42) 3220-4800

e-mail: gaia@utfpr.edu.br

Enviado em: 05/04/2011

Aprovado em: 09/12/2011 